\title{
Progressão da floração e antese de Allium cepa L. (Alliaceae) em Candiota, RS, Brasil
}

\author{
SIDIA WITTER ${ }^{1,4}$, DIETER WITTMANN² e BETINA BLOCHTEIN ${ }^{3}$
}

(recebido: 9 de abril de 2003; aceito: 27 de janeiro de 2005)

\begin{abstract}
Progression of flowering and anthesis of Allium cepa L. (Alliaceae) in Candiota, RS, Brasil). The necessity for pollination by insects depends on the morphology of the flower, the degree of self-fertility and the arrangement of the flowers. We studied the progression of the flowering of Allium cepa L., by measuring the frequency of visits by Apis mellifera $\mathrm{L}$., the anthesis phase and pollen viability. The flowering period in the cultivar Crioula (56 days) was longer than in Bola Precoce (50 days). The duration of the peak of flowering was similar in both cultivars, 15 and 17 days respectively. The correlation between the frequency of visits by A. mellifera and the number of umbels with open flowers was high in Crioula and average in Bola Precoce. The anthesis occured at 7 and 8 days respectively in the two cultivars. Contrary to other observations, we have verified incomplete protandry in both cultivars. Stigmas were receptive when the styles had reached a length of 4-5.5 mm. The average percentage of pollen viability was 90.46 (Crioula) and 80.25 (Bola Precoce).
\end{abstract}

Key words - Allium cepa, anthesis, pollen viability, progression of the flowering

RESUMO - (Progressão da floração e antese de Allium cepa L. (Alliaceae) em Candiota, RS, Brasil). A necessidade de polinização por insetos depende da morfologia da flor, do grau de autofertilidade e do arranjo das flores. A progressão da floração de Allium cepa L., foi avaliada com base na freqüência de visitas por Apis mellifera L., das fases da antese e da viabilidade do pólen. A floração na cultivar Crioula (56 dias) foi mais longa que em Bola Precoce (50 dias). A duração do pico da floração foi semelhante nas duas cultivares, respectivamente 15 e 17 dias. A correlação entre a frequiência de visitas por A. mellifera e o número de umbelas com flores abertas foi alta em Crioula e média em Bola Precoce. A antese foi de 7 e 8 dias, respectivamente, nas duas cultivares. Diferentemente de outras observações, foi verificada protandria incompleta em ambas cultivares. Os estigmas estavam receptivos quando os estiletes mediam 4-5,5 $\mathrm{mm}$ de comprimento. O percentual médio de viabilidade do pólen foi de 90,46 (Crioula) e 80,25 (Bola precoce).

Palavras-chave - Allium cepa, antese, progressão da floração, viabilidade do pólen

\section{Introdução}

$\mathrm{O}$ aumento constante da população exige uma produção crescente de alimentos a partir de novas práticas que permitam o aumento da produtividade (McGregor 1976). Nesse contexto, as técnicas de polinização fazem parte das práticas de manejo de diversas culturas, porém a necessidade de polinização de muitas espécies cultivadas e cultivares não são claramente conhecidas, principalmente aquelas que se desenvolvem nos trópicos (Free 1993).

A cebola (Allium cepa L.), cultivada desde épocas remotas (3.200 a.C.), é originária da Ásia Central,

1. Fundação Estadual de Pesquisa Agropecuária, Rua Gonçalves Dias 570, 90130-060 Porto Alegre, RS, Brasil.

2. Institut für Landwirtschaftliche Zoologie und Bienenkunde, Mellweg 42, 53127 Bonn, Alemanha.

3. Universidade Católica do Rio Grande do Sul, Faculdade de Biociências, Pontifícia Av. Ipiranga 6681, 90619-900 Porto Alegre, RS, Brasil.

4. Autor para correspondência: sidia-witter@fepagro.rs.gov.br especialmente do noroeste da Índia e do Afeganistão (Acosta et al. 1993, Gandin et al. 2001). Seu consumo em forma de condimento é tido como universal e, devido aos seus princípios químicos, é muito utilizada na indústria farmacêutica (Instituto Cepa 1990).

A produção de sementes de cebola na região sul do Rio Grande do Sul destaca-se pela grande importância econômica e, em função da mão de obra requerida, também se reveste de grande relevância social, sendo esta região considerada a mais problemática no Estado, no que tange aos aspectos sócio-econômicos (Gomes 1998). A região geoeconômica de Bagé (latitude $32^{\circ} \mathrm{S}$ ), próxima à fronteira com o Uruguai, apresenta as condições ecológicas ideais para a produção de sementes de cebola (Maluf 1975). O Estado é responsável por $90 \%$ da produção nacional de sementes dessa hortícola e, deste percentual, $40 \%$ a $50 \%$ são produzidas nessa região (Sampaio et al. 1998). Apesar disso, esses autores afirmam que a produtividade média de sementes de cebola na região não tem ultrapassado $350 \mathrm{~kg} . \mathrm{ha}^{-1}$. Em contrapartida, Waters (1972) registrou em 1971 produtividade de $2.242 \mathrm{~kg} \cdot \mathrm{ha}^{-1}$ nos EUA, com 
o uso intensivo de abelhas e sem a presença de floradas competitivas.

Os insetos são indispensáveis para produção de sementes de cebola em escala comercial e Apis mellifera L. tem sido utilizada extensivamente com este propósito (Bohart et al. 1970, Benedek \& Gaal 1972, Gary et al. 1972, Williams \& Free 1974, Ewies \& El-Sahhar 1977). O grau de necessidade de polinização por insetos de uma espécie cultivada em particular depende da morfologia da flor, do nível de autofertilidade e do arranjo das flores na planta ou em plantas adjacentes (Delaplane \& Mayer 2000). Objetivou-se estudar a fenologia da floração de cebola na lavoura, a freqüência de visitas de A. mellifera às flores, os estágios da antese, a receptividade do estigma, a viabilidade do pólen e o número de rudimentos seminais (óvulos) produzidos por ovário.

\section{Material e métodos}

O estudo foi realizado entre outubro e dezembro de 1999 e 2000, em duas lavouras para produção de sementes de cebola, com área de aproximadamente 2,5 ha cada, utilizada no âmbito do programa de produção da empresa Hortec Sementes Ltda, no Município de Candiota, RS, Brasil. Sua localização está compreendida entre as latitudes $30^{\circ} 30^{\prime} \mathrm{S}$ e

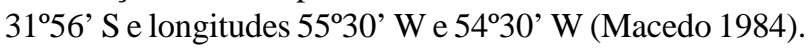

O clima da região é mesotérmico, tipo subtropical, com chuvas distribuídas durante o ano. A temperatura média anual é de $17,6^{\circ} \mathrm{C}$ e a umidade relativa do ar oscila entre $75 \%$ e $85 \%$ (Macedo 1984). O solo é do tipo Podzólico vermelho-amarelo distrófico e eutrófico, com textura média/argilosa e substrato de arenito. Na vegetação adjacente à lavoura de cebola, predominam os campos mistos (Macedo 1984, Gonçalves et al. 1988).

Allium cepa é uma espécie polimórfica, exibindo diferenças quanto ao formato, tamanho, cor e reação ao fotoperiodismo. Trata-se de uma espécie bienal que, sob condições normais, produz bulbos no primeiro ano a partir de sementes e no segundo ano ocorre o florescimento a partir de bulbos (Müller \& Casali 1982, Castellane et al. 1990). As plantas são herbáceas e a diferenciação da fase vegetativa para reprodutiva se evidencia pelo surgimento dos escapos ou hastes florais de número variável. Na extremidade de cada escapo se forma uma inflorescência esférica tipo umbela, com 50 a 2.000 flores, envolta por uma película que se rompe antes da abertura das flores (Müller \& Casali 1982).

As flores de uma umbela se abrem em seqüência irregular, podendo ter duração de duas a mais de quatro semanas (Currah 1981, Müller \& Casali 1982, Acosta et al. 1993). As flores são hermafroditas e protândricas e a autopolinização é possível entre flores de uma mesma umbela ou de diferentes umbelas de uma mesma planta, embora predomine a polinização cruzada (Castellane et al. 1990). Cada flor possui seis estames (três internos e três externos), três carpelos fundidos, um estilete, um estigma e perigônio com seis elementos. O ovário é súpero e contém três lóculos, com dois rudimentos seminais em cada um. Os nectários se localizam na base dos estames e o néctar é acumulado entre os estames internos e externos. O fruto é uma cápsula globular com duas sementes em cada lóculo, sendo estas de coloração externa preta (Müller \& Casali 1982, Castellane et al. 1990, Acosta et al. 1993, Free 1993).

Utilizaram-se para o trabalho duas cultivares de polinização aberta, Crioula Alto Vale (Epagri 362) em 1999 e Bola Precoce (Empasc 352) em 2000, plantadas com espaçamento de $80 \mathrm{~cm}$ entre as linhas e de $15 \mathrm{~cm}$ entre as plantas (figura 1). Na lavoura foi utilizado calcário, fertilizante (NPK) e fungicida. Para o controle de tripes foram realizadas duas aplicações de Decis 25 CE para Bola Precoce e três para Crioula.

A fenologia de floração durante a estação foi registrada em 100 plantas marcadas com fita plástica colorida em 12 pontos distintos, distribuídos na lavoura da seguinte forma: quatro pontos nas extremidades da lavoura, com 11 plantas e oito pontos no interior da lavoura, com sete plantas. As umbelas com até $25 \%$ de flores abertas e aquelas com mais de $25 \%$ de flores abertas foram contadas, em cada ponto marcado, durante a floração de Crioula (27/10/1999 a 22/12/1999) e de Bola Precoce (10/11/2000 a 28/12/2000). Essa metodologia seguiu protocolo proposto por Dafni (1992) e foi adaptada às características da floração de A. cepa. A freqüência dos registros em Crioula foi semanal e em Bola Precoce, a cada quatro dias.

Para determinar a duração da floração em uma umbela, isto é, abertura da primeira e última flor de uma mesma umbela, cinco umbelas $(\mathrm{n}=5)$ de plantas diferentes de A. cepa Crioula foram individualizadas com fita plástica colorida e acompanhadas durante a floração (figuras 2-4).

Foi considerada antese o período entre a abertura da flor e o início da senescência dos estames e pistilo (Faegri \& van der Pijl 1979). O desenvolvimento floral foi estudado marcando-se, ao acaso, 60 botões de seis umbelas de seis plantas distintas das duas cultivares. Os estágios da antese foram acompanhados a partir da observação diária das flores marcadas (figura 3) e comparados com os estágios definidos por Currah \& Ockendon (1978) (tabela 1). As flores foram acompanhadas individualmente durante a plena floração do cultivo (figuras 3-6). Posteriormente, foi realizado um estudo descritivo, estabelecendo-se o padrão de desenvolvimento floral para cada cultivar.

A receptividade do estigma foi verificada coletando-se 45 (Crioula) e 72 (Bola Precoce) flores com estilete entre 1 e $6 \mathrm{~mm}$ de comprimento, de cinco umbelas de diferentes plantas. Logo após a coleta, ainda em campo, cada flor foi destacada da umbela com auxílio de pinça com ponta fina e as tépalas retiradas da flor. Posteriormente, o estigma de cada flor foi colocado em solução de peróxido de hidrogênio (3\%) em uma 
lâmina escavada. Com auxílio de microscópio estereoscópico, verificou-se a formação de bolhas no estigma (Dafni 1992).

Para a contagem do número de rudimentos seminais por lóculo, foram coletadas 100 flores com anteras fechadas e estilete entre 1 e $2 \mathrm{~mm}$, de 10 umbelas de Bola Precoce. As tépalas, anteras, filetes e estilete foram retirados e cada ovário foi cortado transversalmente e examinado sob microscópio estereoscópico.

A viabilidade do pólen foi estimada pelo contraste com solução de carmim acético, distinguindo-se grãos com e sem conteúdo citoplasmático (figura 7). Anteras de dezenas de flores de diferentes plantas foram coletadas, batendo-se cada umbela dentro de um saco plástico por um minuto, em três datas (23/11/1999, 1/12/1999 e 8/12/1999) para Crioula e em duas para Bola Precoce (12/12/2000 e 20/12/2000). Cada amostra foi acondicionada em saco de papel e mantida em estufa a $40{ }^{\circ} \mathrm{C}$ para secagem. Posteriormente, seis anteras de cada amostra foram maceradas diretamente em uma lâmina com duas gotas de carmim acético 4\% (adaptado de Andres et al. 1999), e cobertas por lamínula, levando-se ao microscópio fotônico para observação. De cada data de coleta foram analisadas duas preparações, contando-se a totalidade dos grãos de pólen em cada lâmina.

A freqüência de visitas de $A$. mellifera às flores de cebola foi registrada a partir de uma caminhada lenta ao longo de 420 m de canteiro $(n=138$ plantas $)$, para cada cultivar, através da observação direta das abelhas nas umbelas. Os registros foram feitos durante a floração, por $30 \mathrm{~min}$, a partir das $9 \mathrm{~h}$ $30 \mathrm{~min}, 12 \mathrm{~h} 30 \mathrm{~min}$ e $15 \mathrm{~h}$ 30min, em intervalos de sete dias em Crioula e de 4 dias em Bola Precoce. A freqüência de visitas de A. mellifera em relação ao padrão sazonal da floração de cebola foi analisada utilizando-se testes de correlação (Pearson) e de significância (teste t de Student).

\section{Resultados e Discussão}

O número médio de flores por umbela em Crioula foi de 534,8 \pm 181,0 $(n=39)$ e em Bola Precoce de $613,2 \pm 201,1(\mathrm{n}=28)$. A média de flores por umbela registrada na literatura é variável, a exemplo de 612,2 para Crioula em Santa Catarina (Müller \& Casali 1982) e de outras cultivares híbridas que apresentaram de 213 a 485 flores por umbela (Currah 1981, Ali et al. $1984 \mathrm{e}$ Lorenzon \& Almeida 1993).

Em Allium cepa Crioula, a duração mínima e máxima de floração, considerando-se a abertura das flores de uma umbela, foi de 15 e 25 dias $(n=5 ; x=18,6$; $s=3,7)$. De acordo com outros autores, a duração do episódio de floração em uma umbela pode variar de 16 a 35 dias (Currah \& Ockendon 1978, Ali et al. 1984, Acosta et al. 1993).

A abertura dos botões florais em cada inflorescência de $A$. cepa, em ambas cultivares estudadas, não ocorreu simultaneamente. Constatou-se, paralelamente ao desenvolvimento de flores, a formação de cápsulas e o surgimento de novos botões (figura 5). Por isso, o número de flores abertas em cada umbela nunca atingiu $100 \%$ (figura 3 ).

Cada umbela é constituída por um agregado de numerosas cimeiras compostas de cinco a dez flores, as quais se abrem em seqüência definida. No entanto, a origem das flores em cimeiras distintas causa considerável irregularidade temporal no processo de abertura das flores de uma umbela. Portanto, flores em vários estágios de desenvolvimento, bem como botões e cápsulas podem ser encontrados na umbela durante o pico da floração (Purseglove 1971, Currah \& Ockendon 1978, Castellane et al. 1990, Free 1993).

A duração floração de $A$. cepa Crioula foi oito dias mais curta que em Bola Precoce (tabela 2), semelhante ao registro de Lorenzon \& Almeida (1997) para linhagens híbridas. O maior índice de umbelas com flores abertas foi registrado durante 15 dias para Crioula e 25 dias para Bola Precoce e o maior percentual de umbelas com flores abertas ocorreu no $29^{\circ}$ dia nas duas cultivares, respectivamente 91,41 e 93,25\% (tabela 2). Currah \& Ockendon (1978) consideraram o pico da floração em uma umbela quando pelo menos $30 \%$ das flores estão abertas. Com base neste índice referencial, considerou-se o pico da floração, quando se registrou maior percentual de umbelas com mais de $25 \%$ de flores abertas, observando-se que, em ambas cultivares, este foi semelhante, respectivamente 15 (Crioula) e 17 dias (Bola Precoce) (tabela 2). Considerando-se que a maior parte das sementes é formada durante o pico da floração (Trammel \& Peterson 1973), indica-se que o manejo com polinizadores deva ser intensificado neste período. O momento sugerido para acréscimo de colônias de Apis mellifera na lavoura deve ser determinado a partir do surgimento das primeiras flores. No caso de Crioula, indica-se este manejo no início da terceira semana $\left(22^{\circ}\right.$ dia) com manutenção das abelhas por três semanas. Em Bola Precoce, o procedimento deve iniciar na segunda semana ( $9^{\circ}$ dia) com a permanência das colméias por um mês.

Comparando-se o padrão sazonal da floração de cebola com a freqüência de visitas de A. mellifera, observou-se que na cultivar Crioula a correlação entre a frequiência de $A$. mellifera e número de umbelas com flores $(<25 \%,>25 \%$ e total) foi muito alta $(\mathrm{r}=0,85$; $\mathrm{r}=0,80 ; \mathrm{r}=0,92 ; \mathrm{p}<0,01$ ) (figura 8). Em Bola Precoce a correlação entre a freqüência de $A$. mellifera e o número de umbelas com menos de $25 \%$ de flores abertas não foi significativa. Entretanto, a correlação 


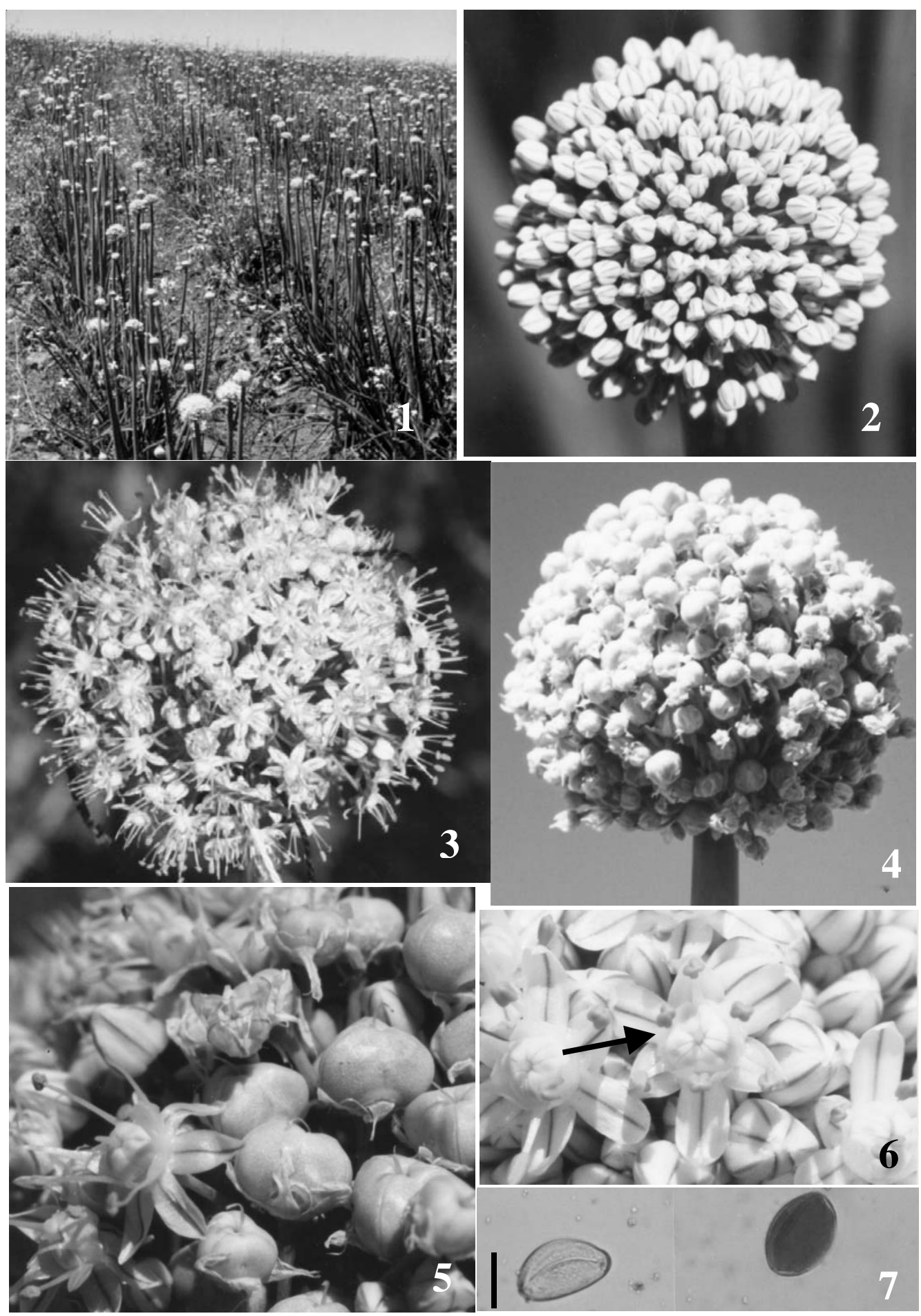

Figuras 1-7. Allium cepa L. cultivar Crioula, em Candiota, RS, 1999. 1. Disposição das plantas na lavoura para produção de sementes. 2. Umbela com botões 3. Umbela com flores em vários estágios de desenvolvimento. 4. Umbela com ovários desenvolvidos (cápsulas). 5. Detalhe de uma umbela com botões, flores e ovários desenvolvidos. 6. Vista superior de flores de cebola. 7. Grãos de pólen de cebola sem conteúdo citoplasmático (esquerda) e com conteúdo citoplasmático (direita), contrastados com solução de carmim acético. Barra $=7 \mu \mathrm{m}$.

Figures 1-7. Allium cepa L. cultivar Crioula, in Candiota, RS, 1999. 1. Positioning of the plants in the field for the production of seeds. 2. Umbels with buds. 3. Umbel with flowers in various stages of development. 4. Umbel with developed ovary (capsule). 5. Umbel with buds, flowers and developed ovaries in detail. 6. Survey of the flowers of onion. 7. Pollen grains of onion without cytoplasm (left) and with cytoplasm (right), stained with acetocarmin. Bar $=7 \mu \mathrm{m}$. 
Tabela 1. Estágios do desenvolvimento floral de Allium cepa proposto por Currah \& Ockendon (1978). Botão estigmático: ausente 0 , indício + , presença ++ .

Table 1. Stages of floral development of Allium cepa proposed by Currah \& Ockendon (1978). Stigmatic knob: absent 0 , trace + , present ++ .

\begin{tabular}{lcc}
\hline Estágio & $\begin{array}{c}\text { Estilete } \\
\text { comprimento } \\
(\mathrm{mm})\end{array}$ & $\begin{array}{c}\text { Botão } \\
\text { estigmático }\end{array}$ \\
\hline 1. abertura (anteras fechadas) & - & - \\
2. começo deiscência (anteras) & $1-2$ & 0 \\
3. final deiscência (anteras) & $4-5$ & 0 \\
4. surgimento do botão & $5-6$ & + \\
5. murchar das tépalas (filetes) & $5-6$ & ++ \\
6. começo do murchar do estilete & $5-6$ & 0 \\
\hline
\end{tabular}

foi considerada média entre a frequiência de $A$. mellifera e o número de umbelas com mais de $25 \%$ e com o percentual total de umbelas com flores abertas $(r=0,65$; $\mathrm{r}=0,65 ; \mathrm{p}<0,05$ ) (figura 9).

A correlação positiva entre a floração e a frequência de abelhas visitantes está em concordância com a literatura a respeito de plantas entomófilas (Free 1993), no entanto, especificamente para A. cepa não se tem registros sobre esta correlação. A correlação existente entre a frequiência de abelhas e a floração das duas cultivares estudadas permite hipotetizar que o manejo de A. mellifera e de floradas competitivas, em áreas de cultivo de cebola, pode aumentar o número de visitas às flores e conseqüentemente elevar os índices de polinização. Currah \& Ockendon (1978) citam que a atividade de diferentes insetos influencia fortemente a proporção de polinização cruzada e autopolinização, de acordo com o estágio de floração alcançado pelas umbelas.

A partir das 60 flores individualizadas verificaram-se perdas de elementos florais impossibilitando a análise dos estágios da antese considerados neste estudo. Assim, o total de flores computadas foi de 23 em A. cepa Crioula e 34 em Bola Precoce.

O comprimento máximo dos estiletes nas duas cultivares foi atingido a partir do segundo dia após a abertura das flores (tabelas 3, 4). O início da deiscência das anteras internas em Crioula ocorreu entre o primeiro e o terceiro dia de antese e das anteras externas, entre o segundo e o quarto dia. Em Bola Precoce o início da abertura das anteras internas e externas ocorreu entre o segundo e quarto dia da abertura da flor. A maioria das flores analisadas em Crioula e Bola Precoce teve o início da deiscência de suas anteras externas $24 \mathrm{~h}$ após o início da deiscência das anteras internas. Em concordância com esses dados, Currah \& Ockendon (1978) destacam que, usualmente, há uma pausa de $24 \mathrm{~h}$ entre os dois eventos. Mas, observou-se em algumas flores das duas cultivares deiscência simultânea das anteras internas e externas.

Na maioria das flores observadas, a disponibilidade de pólen foi maior no segundo e terceiro dias de antese em ambas cultivares. Resultado semelhante foi observado por Currah \& Ockendon (1978) e Currah (1981) que afirmam que o pólen foi liberado nas primeiras $48 \mathrm{~h}$ após a abertura da flor.

Em 13 e 16 flores analisadas de ambas cultivares observou-se a presença de botão estigmático (estigma papiloso) simultaneamente à deiscência das anteras externas. Como a receptividade foi constatada quando os estigmas apresentavam botão estigmático ou indício de botão, verificou-se que em ambas as cultivares a protandria é incompleta (Lloyd \& Webb 1986). Currah

Tabela 2. Quadro comparativo da floração em Allium cepa Crioula (1999) e Bola Precoce (2000), Candiota, RS.

Table 2. Comparison between flowering of Allium cepa Crioula (1999) and Bola Precoce (2000), Candiota, RS.

\begin{tabular}{lcc}
\hline Progressão da floração & Crioula & Bola Precoce \\
\hline Umbelas analisadas & 396 & 519 \\
Início da floração & $27 / 10 / 1999$ & $10 / 11 / 2000$ \\
Floração & 57 dias & 49 dias \\
Início do período com mais da metade do total de umbelas com flores & $22^{\circ}$ dia & $9^{\circ}$ dia \\
Período com mais da metade do total de umbelas com flores & 15 dias & 25 dias \\
Maior percentual de umbelas "com flores & $29^{\circ}$ dia & $29^{\circ}$ dia \\
(Pico da floração) & $17 / 11 / 1999-1 / 12 / 1999$ & $26 / 11 / 2000-12 / 12 / 2000$ \\
& $(15$ dias $)$ & $(17$ dias $)$ \\
\hline
\end{tabular}




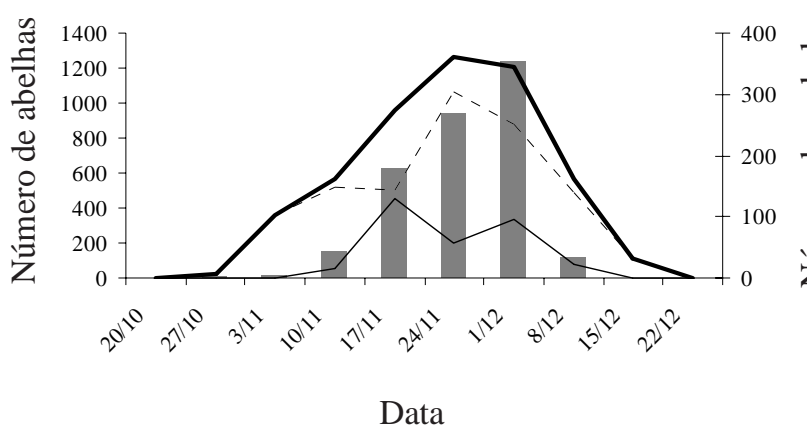

Figura 8. Frequiência de visitas de Apis mellifera ( $\square$ ) em flores de Allium серa Crioula durante a floração; número de umbelas com mais do que $25 \%$ de flores abertas (-); número de umbelas com menos do que $25 \%$ de flores abertas (-..) e o total de umbelas com flores (-).

Figure 8. Frequency of visits of Apis mellifera $(\square)$ to flowers of Allium cepa Crioula during flowering; number of umbels with more than $25 \%$ opened flowers (-); number of umbels with less than $25 \%$ opened flowers (-..) and sum of umbels with flowers (-).

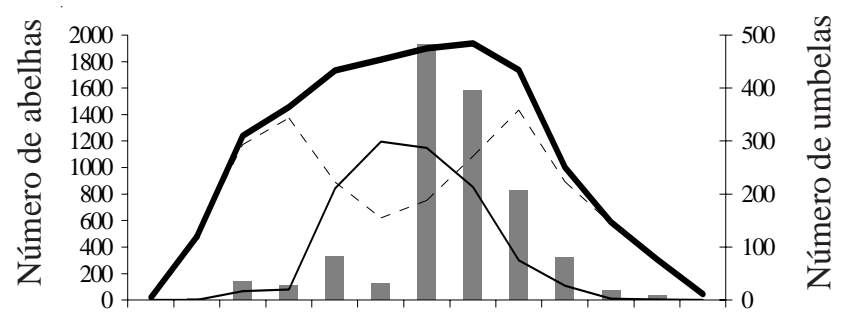

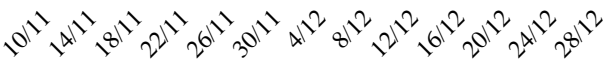

Data

Figura 9. Freqüência de visitas de Apis mellifera ( $\square$ ) em flores de Allium cepa Bola Precoce durante a floração; número de umbelas com mais do que $25 \%$ de flores abertas $(-)$; número de umbelas com menos do que $25 \%$ de flores abertas (-..) e o total de umbelas com flores (-).

Figure 9. Frequency of visits of Apis mellifera $(\square)$ to flowers of Allium cepa Bola Precoce during flowering; number of umbels with more than $25 \%$ opened flowers (-); number of umbels with less than $25 \%$ opened flowers (- - ) and sum of umbels with flowers (-).

Tabela 3. Estágios de antese em Allium cepa Crioula $(\mathrm{n}=23), 1999$, Candiota, RS. $1^{\circ}$ estágio: abertura do botão floral; $2^{\circ}$ estágio: início da deiscência das anteras internas; $3^{\circ}$ estágio: início da deiscência das anteras externas; $4^{\circ}$ estágio: aparecimento do botão estigmático; $5^{\circ}$ estágio: murchamento das tépalas e filetes; $6^{\circ}$ estágio: murchamento do estilete.

Table 3. Stages of anthesis in Allium cepa Crioula $(\mathrm{n}=23), 1999$, Candiota, RS. $1^{\text {st }}$ stage: opening of flower bud; $2^{\text {nd }}$ stage: start of inner anther dehiscence; $3^{\text {rd }}$ stage: start of outer anther dehiscence; $4^{\text {th }}$ stage: appearance of stigmatic knob; $5^{\text {th }}$ stage: withering of tepals and filaments; $6^{\text {th }}$ stage: withering of the style.

\begin{tabular}{|c|c|c|c|c|c|}
\hline \multirow{2}{*}{$\begin{array}{l}\text { Tempo } \\
\text { (dias) }\end{array}$} & \multicolumn{5}{|c|}{ Estágios da antese } \\
\hline & Perianto & & & Estilete / Bot & lo estigmático \\
\hline 1 & $\begin{array}{c}1^{\circ} \text { estágio } \\
(\mathrm{n}=23) 100 \%\end{array}$ & $\begin{array}{l}2^{\circ} \text { estágio } \\
(\mathrm{n}=1) 4 \%\end{array}$ & & & \\
\hline 2 & & $\begin{array}{l}2^{\circ} \text { estágio } \\
(\mathrm{n}=16) 70 \%\end{array}$ & $\begin{array}{c}3^{\circ} \text { estágio } \\
(\mathrm{n}=7) 30,4 \%\end{array}$ & & \\
\hline 3 & & $\begin{array}{l}2^{\circ} \text { estágio } \\
(\mathrm{n}=6) 26 \%\end{array}$ & $\begin{array}{c}3^{\circ} \text { estágio } \\
(\mathrm{n}=15) 65,3 \%\end{array}$ & $\begin{array}{l}4^{\circ} \mathrm{e} \\
(\mathrm{n}=\end{array}$ & $\begin{array}{l}\text { tágio } \\
\text { 13) } 56,5 \%\end{array}$ \\
\hline 4 & $\begin{array}{l}5^{\circ} \text { estágio } \\
(\mathrm{n}=6) 26 \%\end{array}$ & $\begin{array}{l}3^{\circ} \text { estágio } \\
(\mathrm{n}=1) 4,3 \%\end{array}$ & $\begin{array}{c}5^{\circ} \text { estágio } \\
(\mathrm{n}=6) 26 \%\end{array}$ & $\begin{array}{c}4^{\circ} \text { estágio } \\
(n=10) 43,5 \%\end{array}$ & $\begin{array}{c}6^{\circ} \text { estágio } \\
(\mathrm{n}=5) 22 \%\end{array}$ \\
\hline 5 & $\begin{array}{l}5^{\circ} \text { estágio } \\
(\mathrm{n}=14) 61 \%\end{array}$ & $\begin{array}{l}5^{\circ} \text { estágio } \\
(\mathrm{n}=14) 61 \%\end{array}$ & & & $\begin{array}{l}6^{\circ} \text { estágio } \\
(\mathrm{n}=14) 61 \%\end{array}$ \\
\hline 6 & $\begin{array}{l}5^{\circ} \text { estágio } \\
(\mathrm{n}=3) 13 \%\end{array}$ & $\begin{array}{l}5^{\circ} \text { estágio } \\
(\mathrm{n}=3) 13 \%\end{array}$ & & & $\begin{array}{c}6^{\circ} \text { estágio } \\
(\mathrm{n}=3) 13 \% \\
6^{\circ} \text { estágio }(\mathrm{n}=1) 4 \%\end{array}$ \\
\hline
\end{tabular}

\& Ockendon (1978) observaram, em uma cultivar de florescimento tardio que as flores desenvolviam-se rapidamente do estágio 2 (começo da deiscência das anteras) para o 4 (surgimento do botão estigmático), indicando uma protandria menos marcada.
Os resultados obtidos diferem em determinados aspectos de outros estudos onde foi constatado que em flores de A. cepa o estilete possui, aproximadamente, $1 \mathrm{~mm}$ quando a flor abre e alcança um máximo de $5 \mathrm{~mm}$, um a dois dias após a liberação do pólen das anteras. 
Tabela 4. Estágios de antese em Allium cepa Bola Precoce $(\mathrm{n}=34), 2000$, Candiota, RS. $1^{\circ}$ estágio: abertura do botão floral; $2^{\circ}$ estágio: início da deiscência das anteras internas; $3^{\circ}$ estágio: início da deiscência das anteras externas; $4^{\circ}$ estágio: aparecimento do botão estigmático; $5^{\circ}$ estágio: murchamento das tépalas e filetes; $6^{\circ}$ estágio: murchamento do estilete.

Table 4. Stages of anthesis in Allium cepa Bola Precoce $(n=34), 2000$, Candiota, RS. $1^{\text {st }}$ stage: opening of floral bud; $2^{\text {nd }}$ stage: start of inner anther dehiscence; $3^{\text {rd }}$ stage: start of outer anther dehiscence; $4^{\text {th }}$ stage: appearance of stigmatic knob; $5^{\text {th }}$ stage: withering of tepals and filaments; $6^{\text {th }}$ stage: withering of the style.

\begin{tabular}{|c|c|c|c|c|c|c|}
\hline \multirow{2}{*}{$\begin{array}{l}\text { Tempo } \\
\text { (dias) }\end{array}$} & \multicolumn{6}{|c|}{ Estágios da antese } \\
\hline & Perianto & \multicolumn{3}{|c|}{ Estames } & \multicolumn{2}{|c|}{ Estilete / Botão estigmático } \\
\hline 1 & $\begin{array}{c}1^{\circ} \text { estágio } \\
(\mathrm{n}=34) 100 \%\end{array}$ & \multirow{5}{*}{$\begin{array}{c}2^{\circ} \text { estágio } \\
(\mathrm{n}=25) 73,5 \% \\
2^{\circ} \text { estágio } \\
(\mathrm{n}=8) 23,5 \% \\
2^{\circ} \text { estágio } \\
(\mathrm{n}=1) 3 \%\end{array}$} & \multirow{2}{*}{\multicolumn{2}{|c|}{$\begin{array}{l}3^{\circ} \text { estágio } \\
(\mathrm{n}=6) 18 \%\end{array}$}} & \\
\hline 2 & & & & & \multicolumn{2}{|c|}{$\begin{array}{l}4^{\circ} \text { estágio } \\
(\mathrm{n}=1) 3 \%\end{array}$} \\
\hline 3 & $\begin{array}{l}5^{\circ} \text { estágio } \\
(\mathrm{n}=1) 3 \%\end{array}$ & & $\begin{array}{c}3^{\circ} \text { estágio } \\
(\mathrm{n}=22) 64 \%\end{array}$ & $\begin{array}{l}5^{\circ} \text { estágio } \\
(\mathrm{n}=1) 3 \%\end{array}$ & \multicolumn{2}{|c|}{$\begin{array}{l}4^{\circ} \text { estágio } \\
(\mathrm{n}=6) 18 \%\end{array}$} \\
\hline 4 & $\begin{array}{l}5^{\circ} \text { estágio } \\
(\mathrm{n}=7) 21 \%\end{array}$ & & $\begin{array}{l}3^{\circ} \text { estágio } \\
(\mathrm{n}=6) 18 \%\end{array}$ & $\begin{array}{l}5^{\circ} \text { estágio } \\
(\mathrm{n}=7) 21 \%\end{array}$ & \multicolumn{2}{|c|}{$\begin{array}{l}4^{\circ} \text { estágio } \\
(\mathrm{n}=9) 26 \%\end{array}$} \\
\hline 5 & $\begin{array}{c}5^{\circ} \text { estágio } \\
(\mathrm{n}=13) 38 \%\end{array}$ & & $\begin{array}{l}5^{\circ} \text { estágio } \\
(\mathrm{n}=13) 38 \%\end{array}$ & & $\begin{array}{c}4^{\circ} \text { estágio } \\
(\mathrm{n}=11) 32 \%\end{array}$ & $\begin{array}{l}6^{\circ} \text { estágio } \\
(\mathrm{n}=5) 15 \%\end{array}$ \\
\hline 6 & $\begin{array}{c}5^{\circ} \text { estágio } \\
(\mathrm{n}=11) 32 \%\end{array}$ & & $\begin{array}{c}5^{\circ} \text { estágio } \\
(\mathrm{n}=11) 32 \%\end{array}$ & & $\begin{array}{l}4^{\circ} \text { estágio } \\
(\mathrm{n}=6) 18 \%\end{array}$ & $\begin{array}{c}6^{\circ} \text { estágio } \\
(\mathrm{n}=12) 35 \%\end{array}$ \\
\hline 7 & $\begin{array}{l}5^{\circ} \text { estágio } \\
(\mathrm{n}=2) 6 \%\end{array}$ & & $\begin{array}{l}5^{\circ} \text { estágio } \\
(\mathrm{n}=2) 6 \%\end{array}$ & & $\begin{array}{l}4^{\circ} \text { estágio } \\
(n=1) 3 \%\end{array}$ & $\begin{array}{c}6^{\circ} \text { estágio } \\
(\mathrm{n}=13) 38 \%\end{array}$ \\
\hline 8 & & & & & \multicolumn{2}{|c|}{$6^{\circ}$ estágio $(n=4) 12 \%$} \\
\hline
\end{tabular}

Os estames abrem e liberam o pólen em intervalos irregulares antes da receptividade do estigma, configurando a protandria (Jones \& Emsweller 1933, Bohart et al. 1970, Purseglove 1971, Free 1993, Delaplane \& Mayer 2000).

No desenvolvimento da floração em uma umbela há irregularidade na abertura e desenvolvimento das flores. Segundo Currah \& Ockendon (1978), considerando-se a umbela como uma unidade, não há protandria, já que ocorre liberação de pólen de flores vizinhas a outras com estigma receptivo. Embora em uma simples flor possa ser completa, a protandria em uma umbela é improvável. Esses autores discutem a efetividade da protandria em relação ao número de flores em distintas espécies de Allium. Destacam que nas espécies que possuem relativamente poucas flores por umbela, a exemplo de Allium ursinum com seis a 20 flores, a protandria é mais efetiva que em cebola, a qual possui centenas de flores por umbela. Por outro lado, afirmam que umbelas com grande número de flores

Tabela 5. Percentual da viabilidade do pólen de Allium cepa Crioula, em 1999 e Bola Precoce, em 2000, Candiota, RS. Pólen = total de grãos analisados; \% CC = percentual de grãos com conteúdo citoplasmático.

Table 5. Percentage of pollen viability in Allium cepa Crioula, in 1999 and Bola Precoce, in 2000, Candiota, RS. Pollen = number of analysed grains; \% CC = percentage of grains with cytoplasm content.

\begin{tabular}{|c|c|c|c|c|c|c|c|c|c|}
\hline \multicolumn{2}{|c|}{ 23/11/1999 } & \multicolumn{2}{|c|}{ 1/12/1999 } & \multicolumn{2}{|c|}{ 8/12/1999 } & \multicolumn{2}{|c|}{$12 / 12 / 2000$} & \multicolumn{2}{|c|}{$20 / 12 / 2000$} \\
\hline Pólen & $\% \mathrm{CC}$ & Pólen & $\% \mathrm{CC}$ & Pólen & $\% \mathrm{CC}$ & Pólen & $\% \mathrm{CC}$ & Pólen & $\% \mathrm{CC}$ \\
\hline 1233 & 88,73 & 2011 & 87,52 & 1069 & 87,46 & 1083 & 82,09 & 1444 & 82,13 \\
\hline 1100 & 95,91 & 1734 & 91,46 & 1303 & 91,72 & 1103 & 87,22 & 1238 & 69,54 \\
\hline Média & 92,32 & & 89,49 & & 89,59 & & 84,66 & & 75,8 \\
\hline
\end{tabular}


são mais atrativas para insetos e a ação destes aumenta as chances de polinização cruzada.

A quantidade de polinização cruzada que ocorre em cebola varia grandemente (Currah \& Ockendon 1978). van der Meer \& van Bennekon (1972) constataram que flores de cebola com livre visita de insetos resultaram em $8 \%$ a $27 \%$ de autocruzamentos, enquanto com a presença exclusiva de Diptera a autopolinização alcançou $46 \%$ a $71 \%$.

Currah \& Ockendon (1978) sugerem que altas taxas de autopolinização em plantas de polinização aberta induzem a perda de produtividade no cultivo. Um alto índice de autopolinização, na ausência de insetos, reduz a heterozigose e aumenta a expressão de traços (características) deletérios (Kearns \& Inouye 1997).

Se o padrão de protandria nas flores de cebola é incompleto, em ambas cultivares estudadas, e esta não é efetiva quando se considera a umbela como unidade, questiona-se se a autofertilização (autogamia e geitogamia) poderia ser uma das causas da baixa produtividade de sementes na região de estudo. Currah \& Ockendon (1978) supõem que os distintos níveis de cruzamentos constatados em cebola não devem ser causados por diferentes graus de protandria, mas conseqüência do comportamento dos insetos que visitam as flores.

A receptividade dos estigmas de $A$. cepa, em $82,75 \%$ (Crioula) e em 79,16\% (Bola Precoce) das flores, foi constatada quando os estiletes apresentavam botão ou indício de botão estigmático e mediam entre 4 e $5 \mathrm{~mm}$ de comprimento e 4 e $6,0 \mathrm{~mm}$, respectivamente nas duas cutivares. Temporalmente, estas características morfológicas foram verificadas entre o terceiro e quarto dia após o início da antese em Crioula e, entre o segundo e sétimo dia, em Bola Precoce (tabelas 3, 4).

A partir da constatação de que todos os estiletes com botão estigmático mostraram receptividade (testes com $\mathrm{H}_{2} \mathrm{O}_{2}$ ) e da presença do botão estigmático verificada nos estágios da antese (tabelas 3,4), estimou-se a duração da receptividade nas duas cultivares estudadas. Em Crioula a receptividade do estigma foi constatada no terceiro e quarto dia de antese. Em Bola Precoce, receptividade foi verificada entre o segundo e o sétimo dia de antese, tendo sido registrado o maior número de flores receptivas entre o quarto e o sexto dia. Tanto em Crioula como em Bola Precoce a receptividade coincidiu com o quarto estágio de antese.

Segundo Currah (1981), não é possível determinar exatamente quando o estigma se torna receptivo. No entanto, em concordância com os resultados deste estudo, este autor verificou que poucos grãos de pólen se aderem ao estigma no início do estágio 3, enquanto, grande quantidade de grãos aderem ao estigma no final do estágio 4.

$\mathrm{Na}$ busca de causas que expliquem problemas relacionados à produção de sementes de cebola, testouse a hipótese das flores das duas cultivares estudadas não produzirem o número de rudimentos seminais esperados (seis rudimentos/flor) de acordo com a literatura (MacGregor 1976, Acosta et al. 1993, Free 1993). Entretanto, os resultados mostraram que $97 \%$ das flores analisadas produziram seis rudimentos seminais $(\mathrm{n}=100)$. Os $3 \%$ restantes formaram sete ou oito óvulos por flor $(\mathrm{n}=100)$.

$\mathrm{Na}$ cultivar Crioula, nas três datas observadas durante a floração, o percentual médio de grãos de pólen com conteúdo citoplasmático foi de 90,46 (tabela 5). Para a cultivar Bola Precoce o percentual médio alcançado, a partir de duas análises durante a floração, foi de 80,25 (tabela 5).

Segundo Ockendon \& Gates (1976), medir a fertilidade do pólen é difícil e os métodos disponíveis tendem a superestimar sua viabilidade. De acordo com estes autores, o método com carmim acético mostra que o pólen sem citoplasma certamente é estéril, mas o que possui citoplasma não é necessariamente fértil. Portanto, testes mais acurados podem revelar médias mais baixas.

Lorenzon \& Almeida (1997) e Ockendon \& Gates (1976), testando a viabilidade do pólen de cebola com corantes, registraram elevados índices de grãos com conteúdo citoplasmático, entre $84 \%$ e $99 \%$. Em contrapartida, percentuais de viabilidade de pólen de cebola foram inferiores quando testados com fluoresceína, que destaca a integridade do plasmalema (Ockendon \& Gates 1976, Ali et al. 1984). Segundo Ockendon \& Gates (1976), este método possibilita uma melhor indicação de viabilidade do pólen do que a simples presença de citoplasma.

Para Ockendon \& Gates (1976), a viabilidade do pólen de cebola pode ser relacionada a fatores meteorológicos e ao suprimento de nutrientes, sendo que os índices variam grandemente entre flores de uma planta, entre as anteras de uma flor e entre diferentes partes de uma simples antera.

Mann \& Woodbury (1969) verificaram relação entre a idade do pólen e a germinação deste. $\mathrm{O}$ índice de germinação do pólen declina rapidamente após o primeiro dia e aproxima-se de zero no sexto dia de antese. Nye et al. (1971) constataram que o pólen coletado pela manhã foi duas a três vezes mais viável que aquele coletado durante à tarde, entretanto, a 
viabilidade de grãos de pólen provenientes de anteras deiscentes e frescas foi semelhante. Mann \& Woodbury (1969) não verificaram diferenças significativas de viabilidade entre o pólen coletado às $9 \mathrm{~h}$ e às $14 \mathrm{~h} 30 \mathrm{~min}$.

Os resultados, obtidos neste estudo, evidenciam estreita relação entre a floração de cebola e as visitas de Apis mellifera. Portanto, o aumento dos índices de polinização cruzada, com consequiente produtividade de sementes, pode ser promovido com o uso intensivo dessas abelhas durante o pico da floração (cerca de 15 dias/safra).

\section{Referências bibliográficas}

ACOSTA, A., GAVIOLA, J.C. \& GALMARINI, C. 1993. Manual de produccion de semillas horticolas: cebolla. José Crnko, Mendoza.

ALI, M., DOWKER, B.D., CURRAH, L. \& MUMFORD, P.M. 1984. Floral biology and pollen viability of parental lines of onion hybrids. Annals Applied of Biology 104:167-174.

ANDRES, M.V., RODRIGUES, J. \& DURAN, J.M. 1999. Viabilidad del polen del Albaricoquero (Prunus armeniaca L.). Investigacción Agraria, serie Producción y Protección Vegetales 14:25-32.

BENEDEK, P. \& GAAL, E. 1972. The effect of insect pollination on seed onion, with observations on the behaviour of honeybees on the crop. Journal Apicultural Research 11:175-180.

BOHART, G.E., NYE, W.P. \& HAWTHORN, L.R. 1970. Onion pollination as affected by different levels of pollinator activity. Utah Agricultural Experiment Station, Bulletin 482:1-60.

CASTELLANE, P.D., NICOLOSI, W.M., \& HOSEGAWA, M. 1990. Produção de sementes de hortaliças. Faculdade de Ciências Agrárias e Veterinárias da Unesp/Funep, Jaboticabal.

CURRAH, L. 1981. Onion flowering and seed production. Scientific Horticulture 32:26-46.

CURRAH, L. \& OCKENDON, D.J. 1978. Protandry and the sequence of flower opening in the onion (Allium cepa L.). New Phytologist 81:419-429.

DAFNI, A. 1992. Pollination Ecology: A practical approach. Oxford University Press, New York.

DELAPLANE, K.S. \& MAYER, D.F. 2000. Crop Pollination by bees. Cabi, Cambridge.

EWIES, M.A. \& EL-SAHHAR, K.F. 1977. Observations on the behaviour of honeybees on onion and their effects on the seed yield. Journal of Apicultural Research 16:194-196.

FAEGRI, K. \& VAN DER PIJL, L. 1979. The principles of pollination ecology. Pergamon, New York.

FREE, J.B. 1993. Insect pollination of crops. Academic Press, London.
GANDIN, C.L., GUIMARÃES, D.R., THOMAZELLI, L.F. \& BOEING, G. 2001. Escolha da cultivar adequada para produção de cebola. Agropecuária Catarinense $14: 45-48$.

GARY, N.E., WITHERELL, P.C. \& MARSTON, J. 1972. Foraging range and distribution of honeybees used for carrot and anion pollination. Environmental Entomology 1:71-78.

GOMES, P.R. 1998. Viabilidade e conservação do grão de pólen de cebola (Allium cepa L.). Dissertação de Mestrado, Universidade Federal de Pelotas, Pelotas.

GONÇALVES, J.O.N., GIRARDI-DEIRO, A.M. \& GONZAGA, S.S. 1988. Campos naturais ocorrentes nos diferentes tipos de solos no município de Bagé, RS: caracterização, localização e principais componentes da vegetação. Embrapa, Bagé.

INSTITUTO CEPA. 1990. Síntese anual da agricultura de Santa Catarina. Instituto de Planejamento e Economia Agrícola de Santa Catarina, Florianópolis.

JONES, H.A. \& EMSWELLER, S.L. 1933. Methods of breeding onions. Journal of Agricultural Science 7:625-642.

KEARNS, C.A. \& INOUYE, D.W. 1997. Pollinators, flowering plants, and conservation biology. Bioscience 47:297-307.

LLOYD, D.G. \& WEBB, C.J. 1986. The avoidance of interference between the presentation of pollen and stigmas in angiosperms. New Zealand Journal of Botany 24:135-162.

LORENZON, M.C. \& ALMEIDA, E.C. 1993. Caracterização e estágios florais da cebola híbrida. Revista Ceres 40:445-449.

LORENZON, M.C. \& ALMEIDA, E.C. 1997. Viabilidade e germinação do pólen de linhagens parentais de cebola híbrida. Pesquisa Agropecuária Brasileira 32:345-349.

MACEDO, W. 1984. Levantamento de reconhecimento dos solos do município de Bagé, RS. Embrapa, Bagé.

MALUF, W.R. 1975. Produção de sementes de cebola (Allium cepa L.). Esalq, Piracicaba.

MANN, L.P. \& WOODBURY, G.W. 1969. The effect of flower age, time of day and variety on pollen germination of onion, Allium cepa L. Journal American Society Horticultural Science 94:102-104.

MCGREGOR, S.E. 1976. Insect pollination of cultivated crop plants. Agriculture Research Service United States, Washington.

MÜLLER, J.J.V. \& CASALI, V.W.D. 1982. Produção de sementes de cebola. Empasc, Florianópolis.

NYE, W.P., WALLER, G.D. \& WATERS, N.D. 1971. Factors affecting pollination of onions in Idaho during 1969. Journal American Society Horticultural Science 96:330-332.

OCKENDON, D.J. \& GATES, P.J. 1976. Reduced pollen viability in the onion (Allium cepa). New Phytologist 76:511-517. 
PURSEGLOVE, J.W. 1971. Tropical crops: Monocotyledons. John Wiley and Sons, New York.

SAMPAIO, T.G., SAMPAIO, N.V. \& SOARES, P.F. 1998. Estudo de componentes de rendimento na produção de sementes de cebola (Allium cepa L.). Revista Científica Rural 3:1-7.

TRAMMEL, K.W. \& PETERSON, C.E. 1973. Relationships of blooming rate and duration of pollination to seed yields in onion. Hortiscience 8:270.
VAN DER MEER, Q.P. \& VAN BENNEKON, J.L. 1972. Influence of the environment on the percentage of selffertilisation in onions and some consequences for breeding. Euphytica 21:450.

WATERS, N.D. 1972. Honey Bee activity in blooming onion fields in Idaho. American Bee Journal 112:218-219.

WILLIAMS, I.G. \& FREE, J.B. 1974. The pollination of onion (Allium cepa L.) to produce hybrid seed. Journal of Applied Ecology 11:409-417. 